\title{
A Survey on Fabrication Practices of Cladded Components from Nuclear and Non-nuclear Industry
}

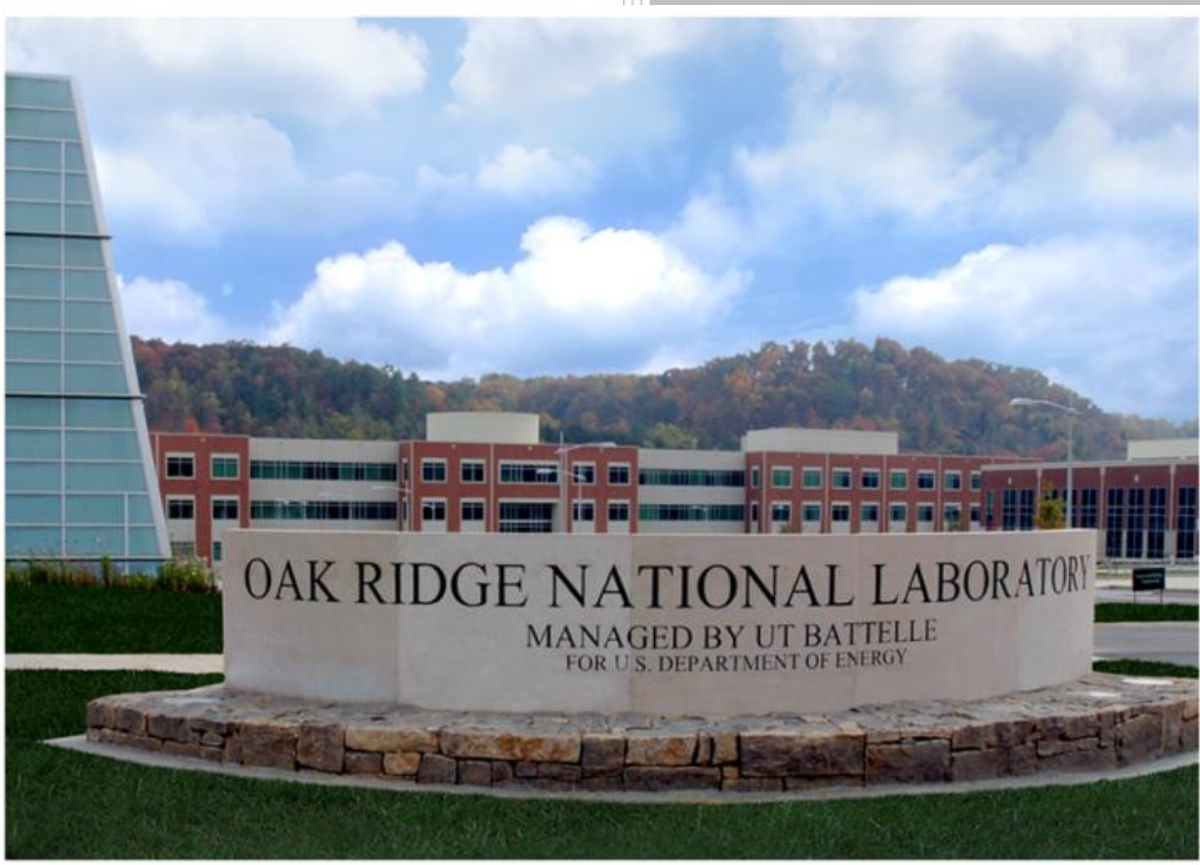

Approved for public release. Distribution is unlimited.

Zhili Feng

Yanli Wang

February 15, 2019 


\title{
DOCUMENT AVAILABILITY
}

Reports produced after January 1, 1996, are generally available free via US Department of Energy (DOE) SciTech Connect.

Website http://www.osti.gov/scitech/

Reports produced before January 1, 1996, may be purchased by members of the public from the following source:

\author{
National Technical Information Service \\ 5285 Port Royal Road \\ Springfield, VA 22161 \\ Telephone 703-605-6000 (1-800-553-6847) \\ TDD 703-487-4639 \\ Fax 703-605-6900 \\ E-mail info@ntis.gov \\ Website http://www.ntis.gov/help/ordermethods.aspx
}

Reports are available to DOE employees, DOE contractors, Energy Technology Data Exchange representatives, and International Nuclear Information System representatives from the following source:

Office of Scientific and Technical Information

PO Box 62

Oak Ridge, TN 37831

Telephone 865-576-8401

Fax 865-576-5728

E-mail reports@osti.gov

Website http://www.osti.gov/contact.html

This report was prepared as an account of work sponsored by an agency of the United States Government. Neither the United States Government nor any agency thereof, nor any of their employees, makes any warranty, express or implied, or assumes any legal liability or responsibility for the accuracy, completeness, or usefulness of any information, apparatus, product, or process disclosed, or represents that its use would not infringe privately owned rights. Reference herein to any specific commercial product, process, or service by trade name, trademark, manufacturer, or otherwise, does not necessarily constitute or imply its endorsement, recommendation, or favoring by the United States Government or any agency thereof. The views and opinions of authors expressed herein do not necessarily state or reflect those of the United States Government or any agency thereof. 
Materials Science and Technology Division

\section{A SURVEY ON FABRICATION PRACTICES OF CLADDED COMPONENTS FROM NUCLEAR AND NON-NUCLEAR INDUSTRY}

Zhili Feng and Yanli Wang

February 15, 2019

Prepared by

OAK RIDGE NATIONAL LABORATORY

Oak Ridge, TN 37831-6283

managed by

UT-BATTELLE, LLC

for the

US DEPARTMENT OF ENERGY

under contract DE-AC05-00OR22725 



\section{CONTENTS}

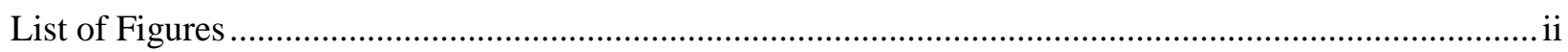

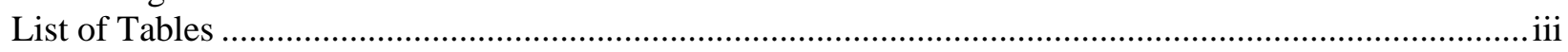

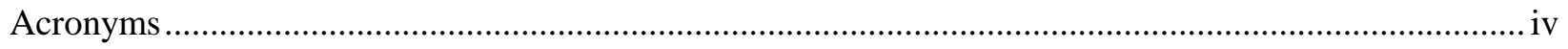

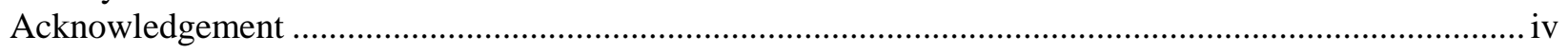

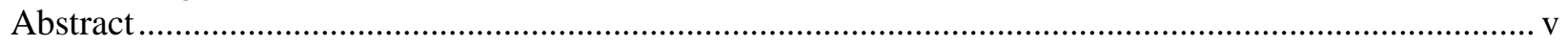

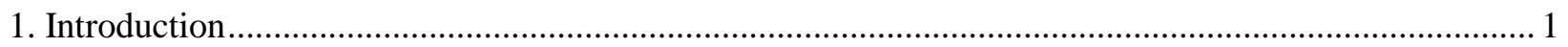

2. Survey of Cladding Technologies for Nuclear and Non-Nuclear Applications.................................... 2

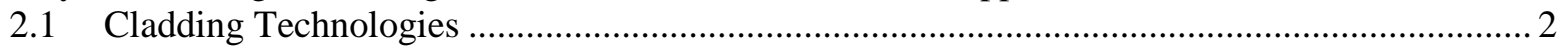

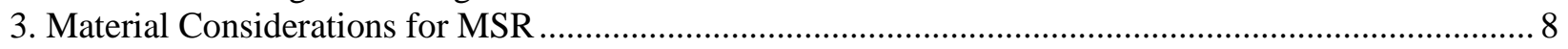

3.1 Candidate Structural Materials for MSR .................................................................... 9

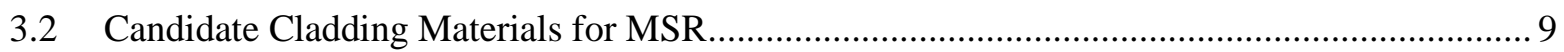

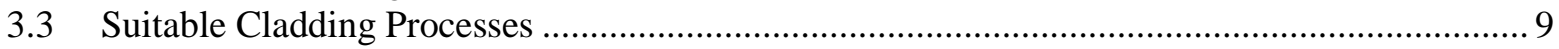

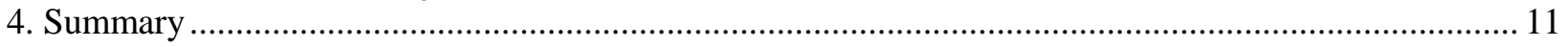

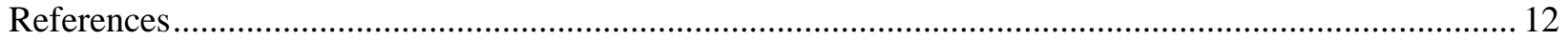




\section{LIST OF FIGURES}

Figure 1 Weld cladding with submerged arc welding using strip electrode ............................................ 3

Figure 2 Comparison of deposition rates for various weld cladding processes.......................................... 3

Figure 3 Composition changes in a 5-layer Nickel clad on S316 by GTAW process................................ 4

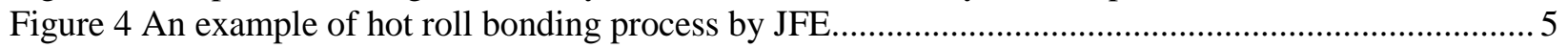

Figure 5 Commercially available explosion bonding material combinations........................................ 7

Figure 6 Lack of interface bonding by chemical vapor deposition process............................................. 11 


\section{LIST OF TABLES}

Table 1 Maximum length of nickel and nickel alloy cladded steel plate per JFE................................... 6

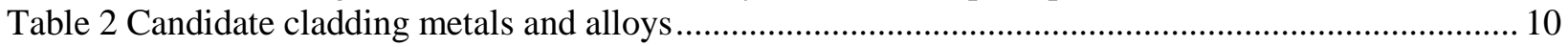

Table 3 Selected properties of candidate clad material and base structural metal for MSRs ................... 11 


\section{ACRONYMS}

ART Advanced Reactor Technologies

ASME The American Society of Mechanical Engineers

ASTM

DOE

MSBR

MRS

ORNL

SFR

American Society for Testing and Materials. (aka, ASTM International)

Department of Energy

Molten Salt Breeder Reactor

Molten Salt Reactor

Oak Ridge National Laboratory

Sodium Fast Reactor 


\section{ACKNOWLEDGEMENT}

The research was sponsored by the U.S. Department of Energy, under contract No. DE-AC05-

00OR22725 with Oak Ridge National Laboratory (ORNL), managed and operated by UT-Battelle, LLC. Programmatic direction was provided by the Office of Nuclear Energy.

The authors gratefully acknowledge the support provided by Alice Caponiti, Director, Office of Advanced Reactor Technologies (ART), Sue Lesica, Federal Manager, ART Advanced Materials Program, A. L. Qualls of ORNL, National Technical Director, ART Fast Reactors Campaign, and Sam Sham of ANL, ART Technology Area Lead on Advanced Materials.

The authors acknowledge George Young of Dominion Engineering Inc for valuable discussions and inputs related to candidate materials considered in this work. 


\begin{abstract}
Integral claddings are used to provide corrosion protection for pressure vessels in nuclear and non-nuclear applications. In this work, a survey was carried out on the fabrication practice of cladded components from nuclear and non-nuclear industry, to provide the baseline reference point for the development of design and fabrication practices of cladding MSR coolant boundary components and core support structures. Gap analysis on applying these fabrication procedures to MSR applications was carried out, with emphasis on fabrication procedures that can lead to desired quality and metallurgical properties and also be applied commercially.

This report fulfills the FY18 milestone M4NT-18OR070502031: “Complete a survey on fabrication practice of cladded components from nuclear and non-nuclear industry" under the ORNL work package NT-18OR07050203 - Cladded Component Design and Fabrication Practice - ORNL.
\end{abstract}




\section{INTRODUCTION}

Molten salt reactor (MSR) is one of the promising advanced reactor concepts, in which molten salts are used as the primary and/or secondary coolant. The reactor designs are often limited by the availability of structural materials that have both adequate elevated temperature strengths and corrosion resistance to molten salts. Current metallic materials permitted for the construction of elevated temperature components of nuclear reactors contained in Section III Division 5 of the ASME Boiler and Pressure Vessel Code (BPVC) are limited, and may not be considered optimum for corrosion resistance with respect to molten salts, with or without the dissolved fuel, for molten salt reactor systems.

As approval of new structural materials will require comprehensive and long-term test data before these new materials can be used for MSR coolant boundary components and core support structures, a clad or overlay of corrosion resistant materials on existing code qualified base metals could be an attractive option. A cladded or overlay structure would combine the desirable properties of the clad materials (corrosion resistance) and the base metal (load bearing) to meet the performance requirements of MSR. Testing requirements of cladding materials could be less demanding than "load bearing" base metals. Hence, such an option could potentially shorten the development and deployment time lines for molten salt reactors.

In this report, a cladded component refers to a layer of corrosion resistant material integrally bonded to the surface of the base metal substrate (the load bearing structural material). An integral clad is a composite product where the corrosion resistant material forms a metallurgical bond with the base metal substrate. Clad for MSR coolant boundary components and core support structures are likely of the integral clad type, for both structure integrity and heat transport considerations.

Cladding or weld overlay has been widely used in the industry, both non-nuclear and nuclear, for corrosion protection and other purposes. There are a number of industry accepted cladding/overlay fabrication technologies and practices including those specified relevant codes and standards. For example, rules for the design and construction of cladded components are provided in ASME BPVC Section VIII for non- nuclear pressure vessel applications. ASTM specifications are available, e.g., A26512, "Standard Specification for Nickel and Nickel-Base Alloy-Clad Steel Plate," [1] and B898-11, "Standard Specification for Reactive and Refractory Metal Clad Plate," [2] for non-nuclear applications. The services and applications of cladded non-nuclear pressure vessels are extensive. For example, clad steel plates have been utilized worldwide in processing vessels, heat exchangers, tanks and variety of material handling and storage facilities. Various forms of clad, weld overlay, and lined steel have been widely used in the chemical, oil refining and chemical transport, and oil/gas production.

Cladding on a structural material for corrosion protection is also used in the nuclear power industry [3]. For example, pressurized-water reactors are constructed from carbon or low alloy steels with internals cladded with a stainless-steel layer to improve chemical compatibility with borated primary coolant water.

The operating conditions and service environments of MSR systems are expected to be more severe, placing added demands on the structural integrity of the construction materials. Hence, while design practice and service experience of cladded components from the past industry practices can be leveraged, they need to be expanded for elevated temperature and corrosive nuclear service environment of MSR.

The objective of this work is to survey and evaluate fabrication techniques and industry practices of integral cladded components from nuclear and non-nuclear industry to establish a reference point for the development of design and fabrication practices of cladding MSR coolant boundary components and core support structures. Technology options and gaps for cladding MSR components are examined, with emphasis on fabrication methods and options that has the potential to commercially produce cladded components for MSR services with desired quality and properties. 


\section{SURVEY OF CLADDING TECHNOLOGIES FOR NUCLEAR AND NON-NUCLEAR APPLICATIONS}

In this section, a brief survey of cladding technologies is presented relevant to the cladding of MSRs. The survey is not meant to be exhaustive but illustrates a variety of cladding techniques that are generally available commercially, and may potentially be employed for MSRs.

Clad material design for corrosion control can be categorized as follows: noble metal clad systems, corrosion barrier systems, sacrificial metal systems, transition metal systems, and complex multilayer systems. The choice of a material for a particular application depends on a number of factors such as cost, availability, appearance, strength, fabricability, electrical and thermal properties, mechanical properties, and of course corrosion resistance performance. The selection of a cladding process would need to consider the choice of material combinations, as well as the geometry and configuration of the cladded components. It is important to recognize that the cladding process and the procedure, process parameters/conditions could have significant impact on the performance of the cladded components.

\subsection{CLADDING TECHNOLOGIES}

Industry over the years has developed a wide range of cladding/overlay technologies and practices for nuclear and non-nuclear applications, including extensive lists of technologies that are in relevant codes and standards. The principle commercially available cladding techniques include hot roll bonding, cold roll bonding, explosive bonding, centrifugal casting, brazing, and weld overlaying. Adhesive bonding, extrusion (co-extrusion), and hot isostatic pressing are also used to produce cladded components. Thermal spray, cold metal spray, and their variants are suitable industry practices for certain material combinations and certain application scenarios. For thin-film coating, techniques such as electroplating, electroless plating, physical vapor deposition including vacuum evaporation and sputtering, and chemical vapor deposition are available. There are a number of reference handbooks that provide general descriptions of different cladding or coating processes, for example, the ASM Metal Handbook Volumes 5, 6, and 13; and ASM Specialty Handbook on Stainless Steels [4,5]. Commercial manufacturers and trade organizations also provide useful information on the cladding technologies used for their products and services, with examples given in [6-8].

The cladding processes can be broadly divided into three different categories [5]. The first category involves bulk melting to bond two materials together. In welding overlay, casting and brazing, one of the metals to be joined is molten when a metal-to-metal bond is achieved. Part of the other metal at the bonding interface can be also in molten state. Weld overlay refers to the deposition of a filler metal on a base metal (substrate) to improve some desired properties to the surface that is not intrinsic to the underlying base metal. There are several sub-categories of weld overlay. Weld cladding usually denotes the application of a relatively thick layer $(>3 \mathrm{~mm})$ of weld metal for the purpose of providing a corrosionresistance surface. Hardfacing is a form of weld overlaying/surfacing that produces a thinner surface coating than a weld cladding for the purpose of reducing wear, abrasion, impact, erosion, or cavitation. There are a number of welding processes for weld cladding, such as submerged arc welding, flux-cored arc welding, plasma arc welding, electroslag welding, and laser beam cladding. Figure 1 shows an example of weld cladding of a vessel internal by submerged arc welding process using strip electrode. Figure 2 lists different weld cladding processes and their typical deposition rates. For very large areas, strip welding with either submerged arc or electroslag techniques is the most economical, however with relatively high dilution.

In weld cladding and other clad processes involving bulk melting of the substrate, an important factor to consider is the dilution effect - the clad layer is mixture in chemistry of the filler metal and the melted base metal, resulting in the clad layer with chemistry and microstructures that are different from either the filler metal or the base metal. 


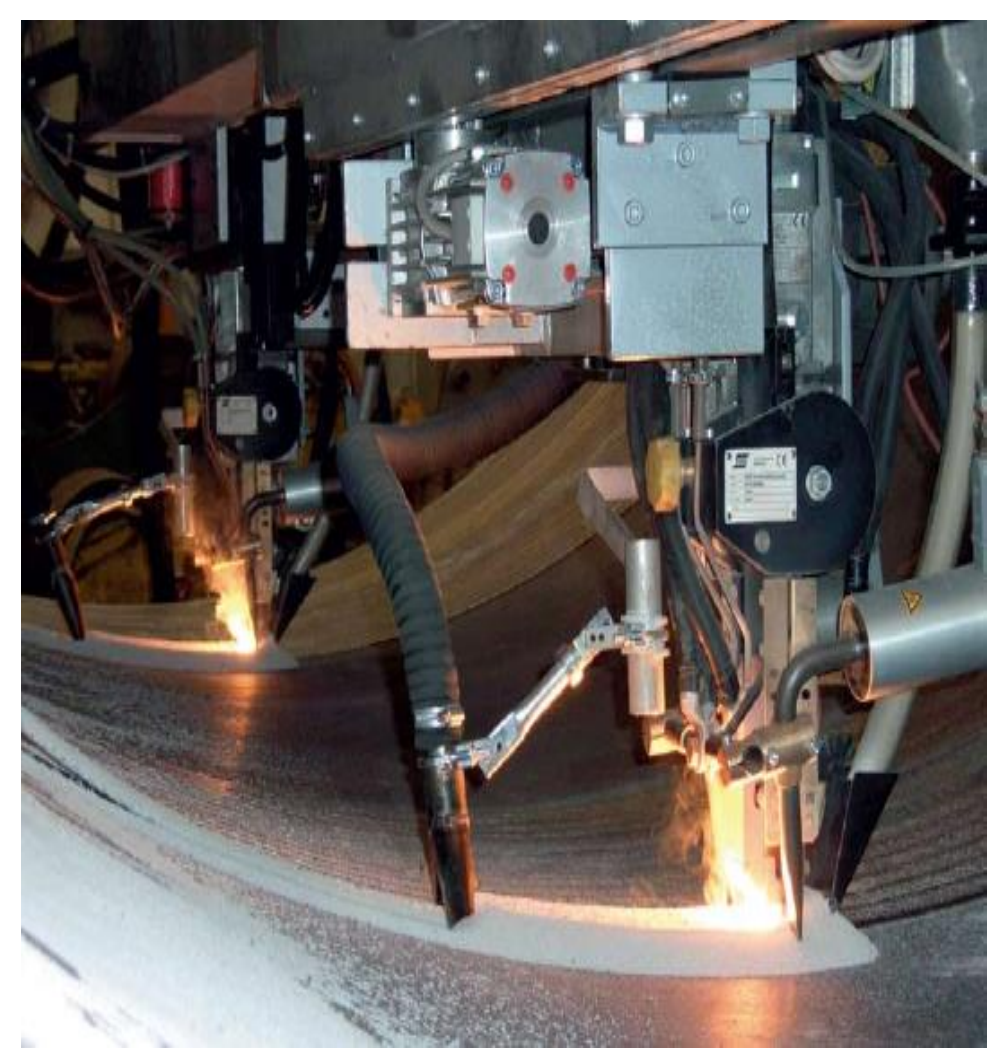

Figure 1 Weld cladding with submerged arc welding using strip electrode [3]

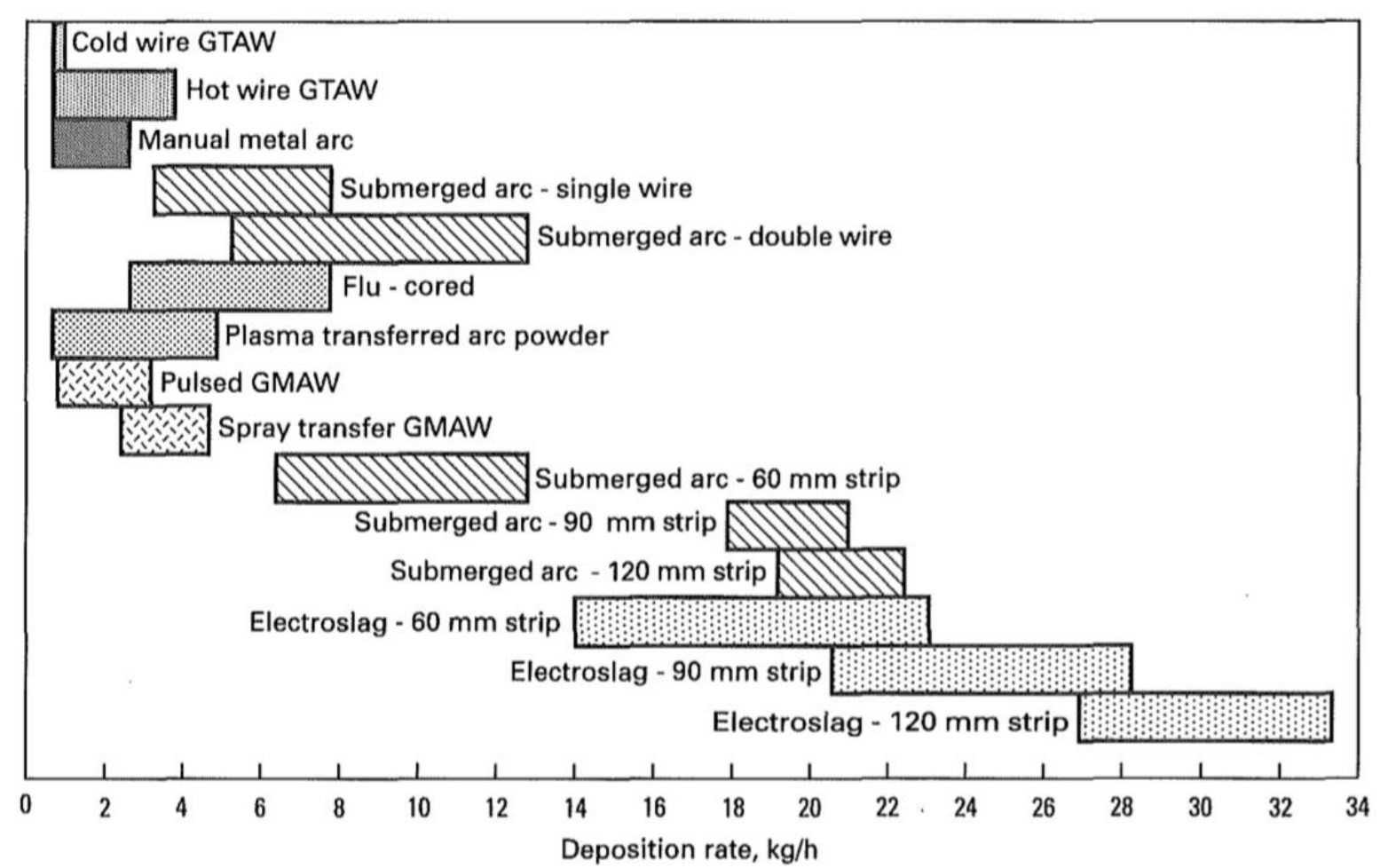

Figure 2 Comparison of deposition rates for various weld cladding processes. [8] 


$$
\% \text { dilution }=\frac{x}{x+y} \times 100
$$

where $\mathrm{x}$ is the amount of base metal melted and $\mathrm{y}$ is the amount of filler metal added.

The dilution could have significant effects on the performance of the clad layer such as corrosion resistance, microstructure and mechanical properties. It is therefore very important to understand how the dilution of the filler metal with the base metal affects the performance of the clad layer as results of composition and metallurgical changes. In addition to surface corrosion resistance, dilution would potentially cause manufacturing issues such as the likelihood of hot cracking. It also would have impact on the mechanical properties and microstructures of the clad layer. For example, the formation of brittle phases and other microstructure features at the interface would influence the bond integrity. There are also well-known examples that inter-diffusion of alloying elements across the interface at elevated service temperature during long period of service (years or longer) causes long-term microstructure and phase stability issues and/or formation of new phases, degrading the performance of the clad.

In practice, multiple layers of weld clad are often used to mitigate the dilution effect. As the dilution of each successive clad layer decreases, it is possible to use multilayer cladding so that the outmost clad layer (or layers) has the chemistry necessary to meet the corrosion and other performance requirement. Figure 3 presents an example of the composition changes in a multiple layer weld clad of commercially pure Ni filler metal (ERNi-1) onto stainless steel 316H base metal [9]. In this particular example, 3 weld clad layers ( 6-mm thick) are necessary to reduce the dilution effect so that the composition in the top of the clad reaching the chemistry of the filler metal. The economics of weld cladding would depend on achieving the specific chemistry at the highest practical deposition rate in a minimum number of layers.

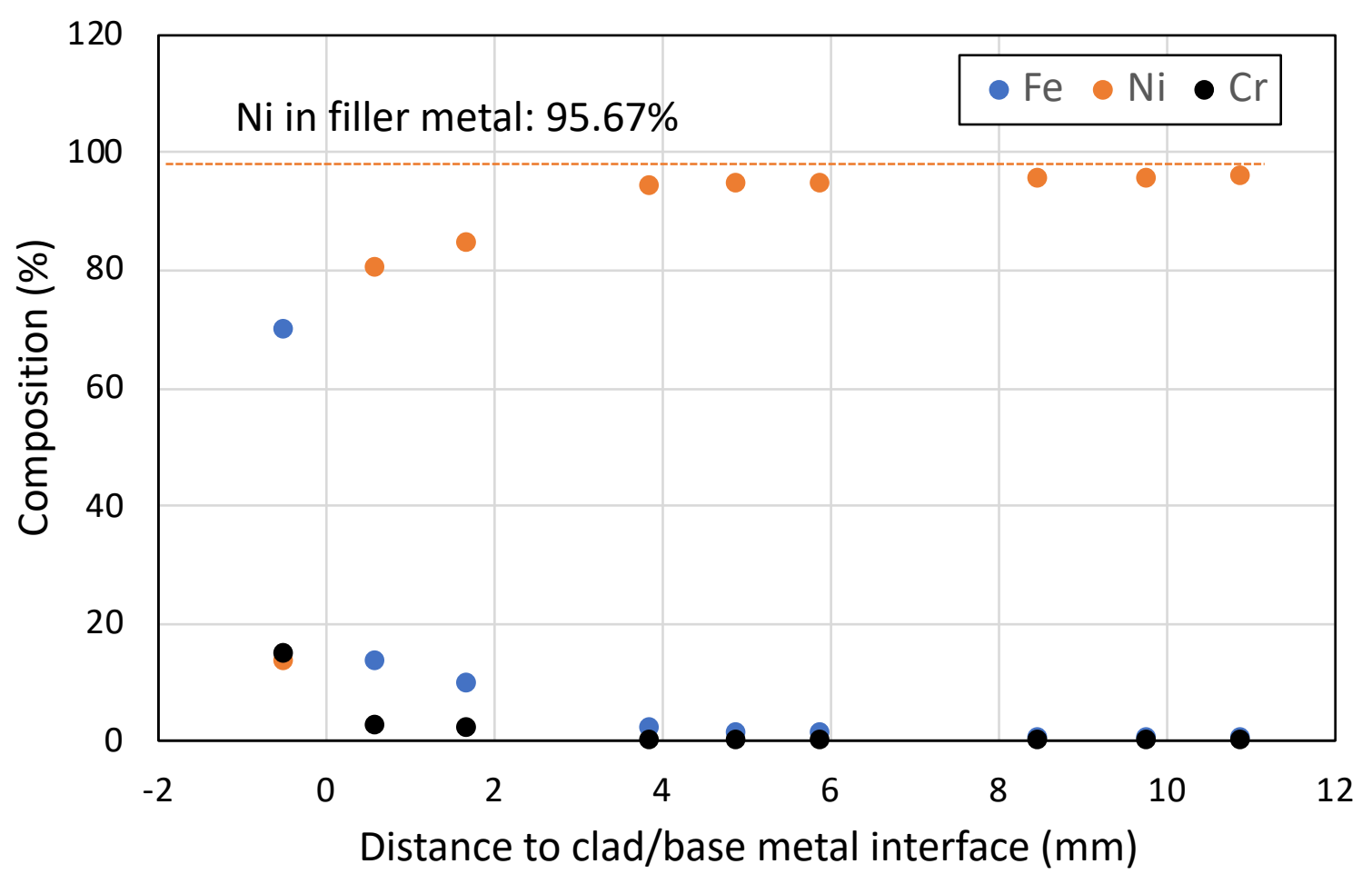

Figure 3 Composition changes in a 5-layer Nickel clad on S316 by GTAW process [9].

It is important to note that each weld cladding process has an expected dilution factor range. The specific cladding process conditions would also influence the extent of dilution for a given process. Because of the importance of dilution, each welding parameter must be carefully evaluated when developing the weld 
cladding procedure for a given application. The welding parameters will need to be recorded in detail during fabrication to ensure quality weld clad be produced.

Welding cladding is an excellent way to improve properties to the surface of a substrate when the cladding material is considered "metallurgically" compatible with the substrate. Examples of metallurgically compatible material combinations include cladding stainless steel or nickel alloys on structural steels. On the other hand, weld cladding of vastly different material combinations, such as Al and steel, are challenging if not possible. The drastic difference in melting points of steel and $\mathrm{Al}$ makes the formation of strong bonding or adhesion difficult. The formation of brittle intermetallic phases between steel and $\mathrm{Al}$ also creates rather weak bond that may not meet the strength and integrity requirement of the clad. For such cases, solid-state bonding process may provide an alternative solution.

The second category of cladding technologies involves no bulk melting so they are considered as solidstate cladding process. The bond is achieved by forcing clean oxide-free metal surface into intimate contact to form metallurgical bonding. The solid-state processes generally involve some forms of deformation to break up surface oxide, to create metal-to-metal contact, and to heat in order to accelerate diffusion across the interface for bonding. They differ in the amount of deformation and heat used to form the bond, and in the method of bringing the metals into intimate contacts. It is noted that although the bulk of the materials are solid, local microscopic level melting may take place at the bonding interface, depending on the specifics of fabrication conditions in a solid-state bonding process.

Hot roll bonding is a solid-state cladding/bonding process. It is one of the most important commercially cladding technologies. Hot roll bonding accounts for more than $90 \%$ of the stainless-clad steel plate production worldwide [8]. It is also known as the heat and pressure process because the principle involves preparing the carefully cleaned cladding components in the form of a pack or sandwich, heating to the plastic range, and bring the clad material and the substrate material into intimate contact, either by pressing or by rolling. A product so formed is integrally bonded at the interface. The clad surface is in all aspects (corrosion resistance, physical properties, and mechanical properties) the equal of the parent clad material [5]. Figure 4 presents an example of major steps in hot roll bonding manufacturing process - it is the process by JFE for stainless clad steel plate production. The cladded plates produced by hot roll bonding can be further processed to form different shapes for pressure vessel applications.

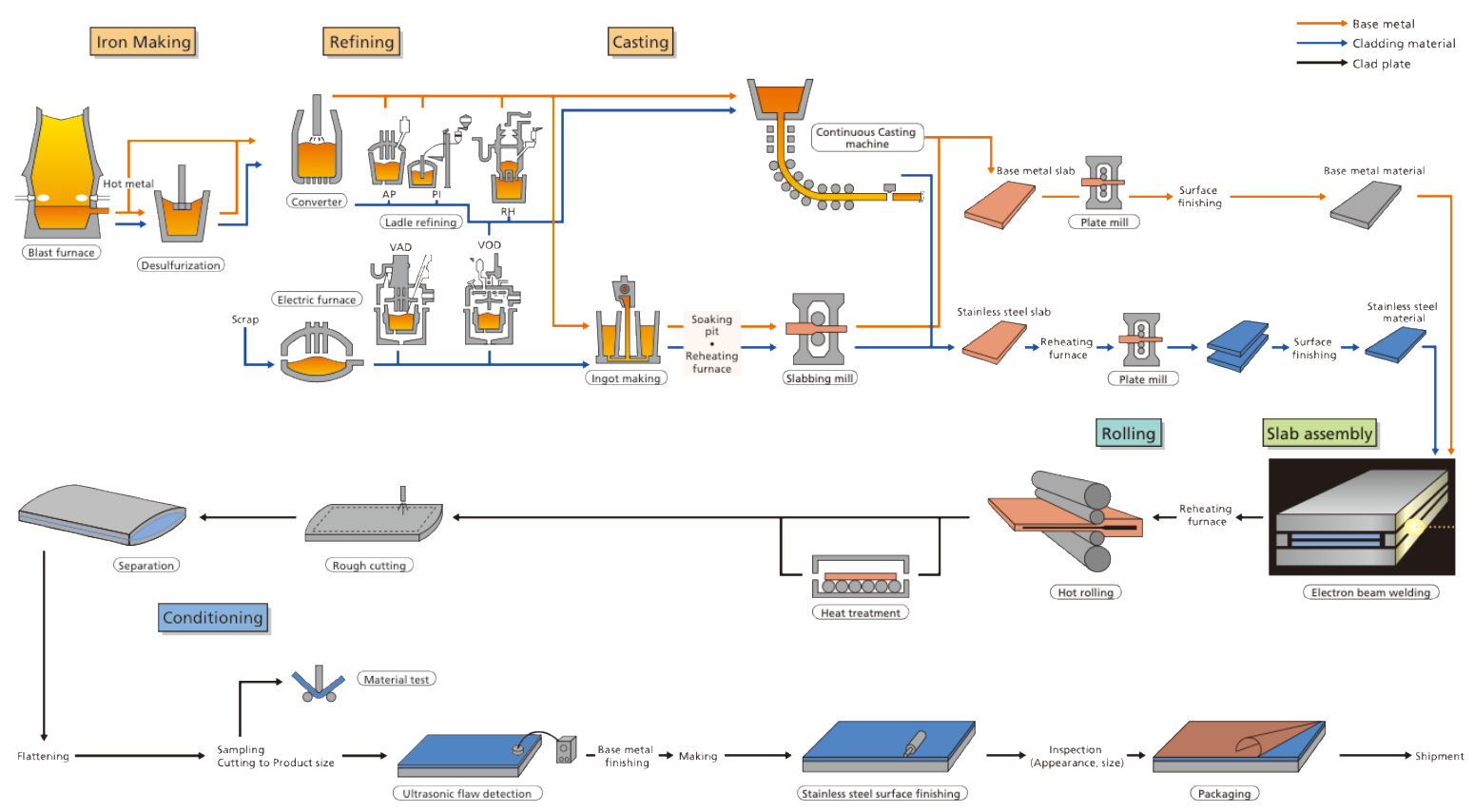

Figure 4 An example of hot roll bonding process by JFE [7] 
Hot roll bonding is widely used to clad steels with a corrosion resistance layer. A wide range of ASTM/ASME pressure vessel steel and structural steel plates can be cladded by hot roll bonding. Clad materials include different grades of stainless steels (ferritic, martensite, and austenite grades), nickel and nickel alloys, and Ti alloys [5, 7]. In principle, hot roll bonding can be used to clad pure nickel and nickel alloys on to stainless steels, which is relevant to MSR coolant boundary components and core support structures.

The sizes of hot roll bonded plates are generally depending on the capability of manufacturers. Table 1 shows as an example the sizes of hot roll bonded plates by JFE. The clad materials are nickel or nickel alloy, on pressure vessel or structure steels. The cladded plates can be up to 14 meters long, 1 to 4 meters wide, and $6 \mathrm{~mm}$ to $80 \mathrm{~mm}$ thick. The thickness of the cladding material (nickel or nickel alloy) ranges from $1.5 \mathrm{~mm}$ to $10 \mathrm{~mm}$.

Table 1 Maximum length of nickel and nickel alloy cladded steel plate per JFE [7]

\begin{tabular}{|c|c|c|c|c|c|c|c|c|}
\hline \multicolumn{3}{|c|}{ Thickness } & \multicolumn{6}{|c|}{ Width $(\mathrm{mm})$} \\
\hline $\begin{array}{l}\text { Total } \\
(\mathrm{mm})\end{array}$ & \multicolumn{2}{|c|}{$\begin{array}{l}\text { Cladding } \\
\text { material } \\
(\mathrm{mm})\end{array}$} & \multirow[t]{2}{*}{$\begin{array}{c}1000 \\
- \\
2000\end{array}$} & \multirow{2}{*}{$\begin{array}{c}2001 \\
- \\
2500 \\
14\end{array}$} & \multirow[t]{2}{*}{$\begin{array}{c}2501 \\
- \\
3000\end{array}$} & \multirow[t]{2}{*}{$\begin{array}{c}3001 \\
- \\
3500\end{array}$} & \multirow[t]{2}{*}{$\begin{array}{c}3501 \\
- \\
4000\end{array}$} & \multirow[t]{2}{*}{$\begin{array}{c}4001 \\
- \\
4200\end{array}$} \\
\hline $6.0-8.0$ & 1.5 & $-\quad 3.0$ & & & & & & \\
\hline $8.1-10.0$ & 2.0 & $-\quad 4.0$ & \multicolumn{4}{|c|}{14} & & \multirow{5}{*}{ N.A. } \\
\hline $10.1-12.0$ & 2.0 & $-\quad 5.0$ & \multicolumn{5}{|c|}{14} & \\
\hline $12.1-16.0$ & 2.0 & -6.0 & \multicolumn{5}{|c|}{14} & \\
\hline $16.1-18.0$ & 2.0 & -6.0 & \multicolumn{5}{|c|}{14} & \\
\hline $18.1-20.0$ & 2.0 & $-\quad 6.0$ & \multicolumn{4}{|c|}{14} & 13 & \\
\hline $20.1-22.0$ & 2.0 & $-\quad 6.0$ & \multicolumn{4}{|c|}{14} & \multicolumn{2}{|c|}{12} \\
\hline $22.1-24.0$ & 2.0 & -6.0 & \multicolumn{3}{|c|}{14} & 13 & \multicolumn{2}{|c|}{11} \\
\hline $24.1-26.0$ & 2.0 & $-\quad 7.0$ & \multicolumn{3}{|c|}{14} & 12 & \multicolumn{2}{|c|}{11} \\
\hline $26.1-28.0$ & 2.0 & $-\quad 7.0$ & \multicolumn{2}{|c|}{14} & 13 & 11 & \multicolumn{2}{|c|}{10} \\
\hline $28.1-30.0$ & 2.0 & -7.0 & \multicolumn{2}{|c|}{14} & 12 & 10 & \multicolumn{2}{|c|}{9} \\
\hline $30.1-35.0$ & 2.0 & -8.0 & 14 & 13 & 11 & 9 & \multicolumn{2}{|c|}{8} \\
\hline $35.1-40.0$ & 2.0 & -8.0 & 14 & 12 & 10 & 8 & \multicolumn{2}{|c|}{7} \\
\hline $40.1-50.0$ & 2.0 & -8.0 & 11 & 9 & 7 & 6 & \multicolumn{2}{|c|}{5} \\
\hline $50.1-60.0$ & 2.0 & -10.0 & 10 & 8 & 6 & 5 & 4 & \multirow{3}{*}{ N.A. } \\
\hline $60.1-70.0$ & 3.0 & -10.0 & 9 & 7 & 5 & 4 & & \\
\hline $70.1-80.0$ & 3.0 & -10.0 & \multicolumn{4}{|c|}{ Range to be consulted } & & \\
\hline
\end{tabular}

Explosive bonding, also known as explosion welding or explosive cladding, is another commercially available solid-state cladding process potentially suitable for cladding of MSR components. It bonds two or more metals with the aid of explosive. With the very-short-duration, high-energy impulse of an explosion, a high-velocity oblique impact wave drives two surfaces of metal together, simultaneously cleaning away surface oxide films and cause the colliding metal surfaces to flow hydro dynamically when they intimately contact one another in order to promote solid-state bonding. The metal surfaces are compressed together under high pressure from the explosion, and an atomistic bonding between the dissimilar metals is achieved. 
Explosive bonding is an effective method for dissimilar metal combinations that cannot be readily welded or cladded by conventional processes. Figure 5 provides a list of material combinations that can be explosive bonded commercially [5]. It can be used to bond titanium-steel, aluminum-steel and aluminumcopper. It can also be used to weld compatible metals, such as stainless steels and nickel alloys to steel. The cladding metals are typically stainless steel, duplex steel, titanium, aluminum, copper, copper alloys, nickel, nickel alloys, tantalum, and zirconium. Explosive bonding can be applied in different part configurations, such as flat plates, round discs, pipes, and shafts. Additional information on explosive bonding can be found in [10-12].

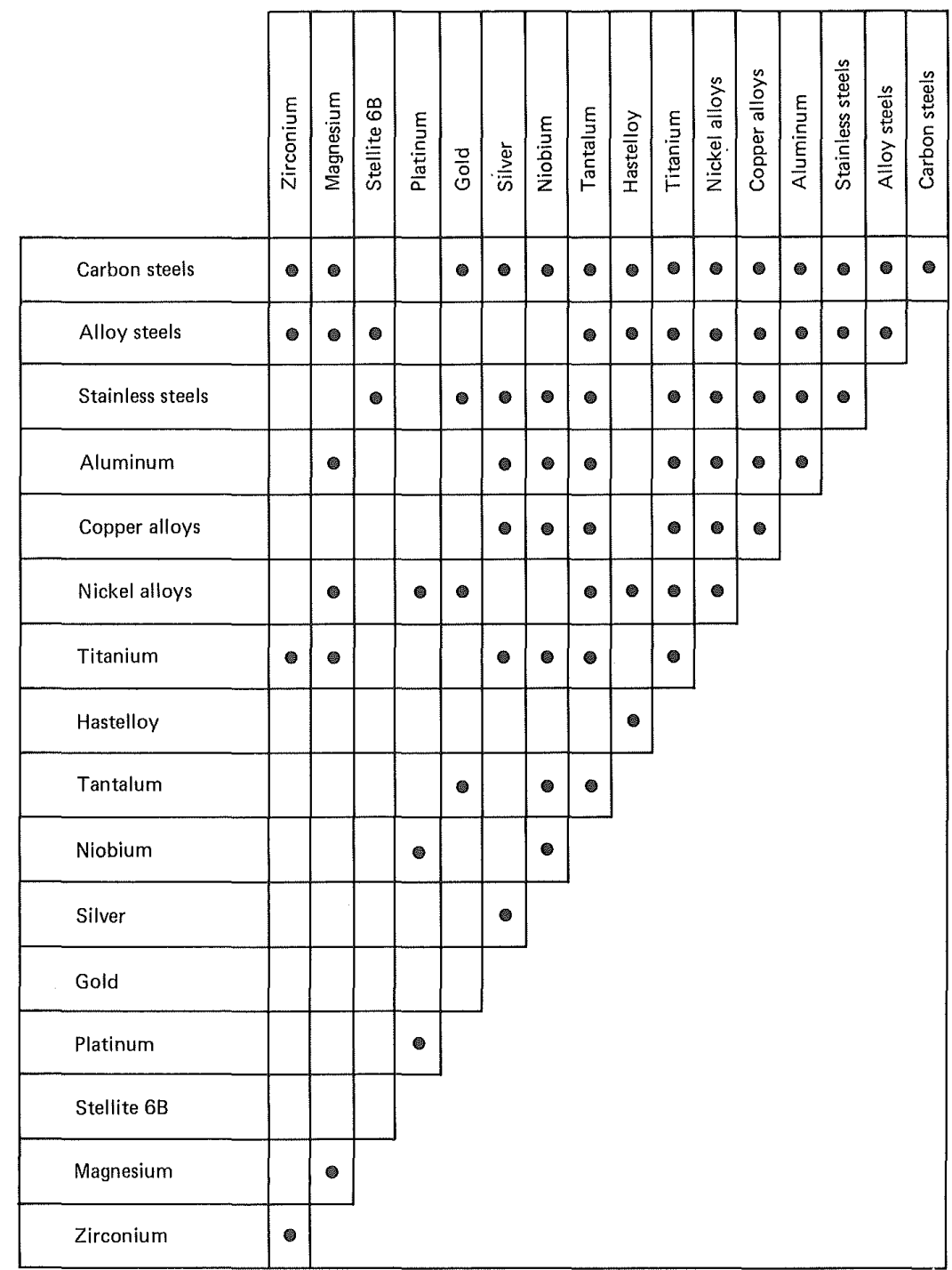

Figure 5 Commercially available explosion bonding material combinations. [5]

Coextrusion is the process of simultaneous extrusion of two or more metals to form an integral product [13]. In modern times, the first important application of the process was for the production of fuel elements for nuclear reactors. In the coextrusion process, a core material is extruded along with the clad material through a convergent die. The concurrent deformation of the core and the clad material results in the formation of an interfacial bonding layer between the core and the cladding. The coextrusion or codrawing process can be carried out at appropriate temperatures for the system of materials under consideration and can be accomplished using conventional extrusion or drawing equipment. Other 
variations, such as friction extrusion or hydrostatic extrusion, are also possible. The coextrusion process is typically carried out using materials with widely different mechanical properties - either hard core/soft clad or soft core/hard clad. Hence, successful coextrusion depends on a number of factors, such as metallurgical and mechanical compatibility of the two materials and a number of process parameters that influence the flow behavior of the two materials. Coextrusion is generally more suited for fabrication of tubes, rods and wires than other bulk components.

In a thermal spray process [14], cladding material in the form of powder, wire, or rod is fed into a torch or a gun, where it is heated to near or above its melting point. A stream of gas propels the resulting molten or nearly molten droplets of material toward the substrate. On impact, the droplets are mechanically deformed and adhere to the surface while overlapping and interlocking during the process of solidification. The total cladding thickness is usually generated in multiple passes and or multiple layers. Thermal spray can be carried out without significant heating of the substrate hence minimizing issue with substrate microstructure and property changes due to cladding process. It can clad relatively complex surfaces of components. However, it requires a line-of-sight process and could be difficult to apply for small diameter tubes. Claddings may have porosity, low density, and relatively high level of impurity which can be a concern for corrosion protection in molten salt environment.

The third category is chemical based surface deposition process. It includes electroplating $[15,16]$, electroless plating [17], physical vapor deposition [18, 19], and chemical vapor deposition [20]. These processes can be suitable to coat nickel and nickel alloys on a substrate. However, they are commonly used to clad or coat thin films, compared to other two categories of cladding processes outlined above.

Due to their solid-state bonding nature, dilution in hot-roll bonding, explosive bonding, coextrusion and other solid-state processes is virtually nonexistent. The same can also be said about the plating and deposition processes. However, inter-diffusion of alloying elements across the bonding interface would still present potential issues with the formation of undesirable microstructures and phases to impair the bond integrity under long-term elevated service temperature conditions. Such aspect would require careful consideration of the cladding process, material selection and through evaluation and test to ensure long-term integrity and performance of the cladded MSR components under indented service conditions.

\section{MATERIAL CONSIDERATIONS FOR MSR}

Current MSR design considers the use of integral clad on current ASME Division 5 construction materials as a potential near-term solution. Information in this section are primarily from [21]. Design and construction rules and analysis methods for cladded structural components are being developed as part of the on-going NE MSR Campaign, ART Advanced Materials program, to ascertain the integrity and corrosion protective functions of the cladding for the anticipated service lifetime and cyclic service conditions in MRS. The design procedure allows the clad to be a non-code qualified material. The design rules also consider property mismatch envelop to exempt the consideration of certain ASME code failure mode for cladding, by means of the so-called "compliant cladding" concept. Acceptance criteria and test data requirement for selected clad and base metal combination are also part of the design and construction rule development. There are a number of factors in materials, design, fabrication, examination and inservice inspection that being investigated for cladded components. Understanding potential material degradation issues caused by mass and fission products transfer across clad/base metal boundary during clad fabrication and plant operation is a key element of research, due to the expected considerable differences in chemistry, microstructure and property of the clad material and the base structural metal. 


\subsection{CANDIDATE STRUCTURAL MATERIALS FOR MSR}

Current ASME Division 5 structural materials in consideration for MSR include the following:

- $\quad 316 \mathrm{H}$ (stainless steels, qualified up to $300,000 \mathrm{~h}$ design lives)

- Alloy 709 (advanced stainless steel, testing being conducted to support code qualification)

- Alloy 800H (Iron-based austenitic alloy, qualified up to 300,000 h design lives)

- Alloy 617 (Ni-based alloy, being balloted by ASME code committees, qualified up to 100,000 h design lives)

\subsection{CANDIDATE CLADDING MATERIALS FOR MSR}

Relative to PWR, MRS operates at lower pressure, higher temperature and very different coolant. There are two primary types of coolant media - fluoride salt based, and chloride salt based [22].

For the Molten Salt Breeder Reactor (MSBR), an early concept developed and tested at ORNL, molten LiF-BeF2-ThF4-UF4 was selected as fuel and coolant. It was recognized that the Ni-base alloys exhibited superior corrosion resistance to this type of molten salt if the salt redox condition was well controlled. Recently, there are a number of advanced MSR concepts being considered by industry and the U.S. DOE that feature molten fluoride salts as the fuel and/or coolant. In general, these systems have many attractive features including low-pressure operation, efficient high-temperature power conversion, and passive heat rejection. The preferred salts for these systems consist of $\mathrm{LiF}$ mixed with other fluorides such as LiF$\mathrm{BeF} 2$ and LiF-ThF4. The corrosion of pure salt is found to be low. However, contaminants caused by ingress of water or oxygen, and neutron irradiation of $6 \mathrm{Li}$ in the salt can make the salt more oxidizing. This may result in the corrosion of transition metals such as $\mathrm{Ni}, \mathrm{Fe}$, and $\mathrm{Cr}$ which are constituents of the structural materials. The released corrosion products in the salt also affect the fuel/coolant properties. Therefore, the material corrosion must be considered when designing a molten salt cooled/ fueled reactor system.

A general consideration in selection of cladding materials in the molten salts would be that the redox potential of the material be higher than that of the salt. Under such conditions, corrosion is not favored. Reactions with radiation are also taken into consideration in selecting the cladding materials. Based on the corrosion potentials and a high-level metallurgical screening, 3 types of metals and their alloys were identified to potentially provide significant corrosion protection in molten salts: $\mathrm{W}, \mathrm{Mo}$, and $\mathrm{Ni}$. W is very noble in both $\mathrm{F}$ and $\mathrm{Cl}$ salts, also tritium permeation barrier. Mo is also very noble in both $\mathrm{F}$ and $\mathrm{Cl}$ salts. $\mathrm{Ni}$ is noble in both $\mathrm{F}$ and $\mathrm{Cl}$ salts, has low strength and is very ductile which is suitable as compliant cladding. However, Ni transmutes to helium under neutron irradiation. There are a number of commercially available alloys based on $\mathrm{W}, \mathrm{Mo}$, and Ni to consider as cladding materials. Their general considerations are given in Table 2, and Table 3.

\subsection{SUITABLE CLADDING PROCESSES}

Fabrication processes and methods for cladding are highly dependent on the material combinations of clad and substrate for MSR. They will also need to suit the physical configuration of the structures.

\section{Ni Based Cladding Materials}

The selected structural materials for MSRs in Section 3.1 (316H, Alloy 709, Alloy 800H and Alloy 617) are iron based austenitic alloys or nickel-based alloys. They are generally considered to be highly compatible with Ni based cladding materials (commercially pure Ni alloy, and Hast $\mathrm{N}$ alloy and its variant). The industry has extensive experience and capability to clad $\mathrm{Ni}$ on these alloys with a variety of cladding techniques. Hot roll bonding can be used to clad plates which can be subsequently formed and 
welded to form structures. Welding overlay can also be readily applied, as demonstrated recently [9]. Dilution control or minimizing the dilution effect during welding overlay to reduce the overall cladding thickness while achieving the desired surface chemistry for sufficient corrosion resistance should be taken into account in selecting welding overlay process and specifying cladding process parameters for a given application. Co-extrusion can be used for tubular structures. These processes should be considered as the first choice, as they are commercially viable, economical and generally produce high quality clads, when compared to other cladding processes. Other alternative cladding processes could be considered for certain special situations where the above processes are difficult to apply. However, these alternative processes would require in-depth evaluation and qualification, as improper selection of processes and cladding processes conditions could lead to potential quality issues, as illustrated in Figure 6.

\section{W and Mo based Cladding Materials}

Cladding W and Mo based materials on the candidate MSR structural materials in Section 3.1 are expected to be challenging. Application of common cladding processes such as hot roll bonding, welding overlay, and co-extrusion has been difficult if not impossible, due to the high temperature strength, relatively low ductility and metallurgical incompatibility of $\mathrm{W}$ and Mo alloys with iron and nickel-based alloys. Explosive bonding of W and Mo alloys are possible, with limited applications. Knowledge of long-term microstructure and composition stability at the bonding interface during plant operation are very limited, and require thorough investigations. Furthermore, as shown in Table 3, the thermal expansion coefficients of $\mathrm{W}$ and Mo are much lower than these of candidate MSR structural materials. Combined with the high strength of $\mathrm{W}$ and Mo, there is a concern of high level of thermal stresses at the bonding interface especially under cyclic thermal variations during the service of MSRs. Such high levels of thermally induced stresses would drive localized creep or creep-fatigue damage at the bonding interface, which may weaken the interface over the expected long-period of MSR operation.

Overall, compared to Ni based cladding materials, development of new and innovative cladding technologies for W and Mo alloy are essential to support the use of W and Mo alloys as clad in MSR.

Table 2 Candidate cladding metals and alloys

\begin{tabular}{|c|c|c|}
\hline Element & Comments & Conclusion \\
\hline $\mathrm{W}$ & $\begin{array}{r}\text { W-Re alloys have some ductility but Re likely has unacceptable } \\
\text { nuclear performance (e.g. Re }(\mathrm{n}, \gamma) \rightarrow \mathrm{Os})\end{array}$ & $\begin{array}{c}\text { Commercially Pure } \\
\text { (CP) W }\end{array}$ \\
\hline $\mathrm{Mo}$ & $\begin{array}{c}\text { Mo-Re alloys have some ductility but Re likely has unacceptable } \\
\text { nuclear performance. Mo-TZM is commercially available alloy. }\end{array}$ & Mo-TZM \\
\hline $\mathrm{Ni}$ & $\begin{array}{c}\text { Low Cr Ni alloy have demonstrated corrosion performance in F } \\
\text { salts and likely have superior weldability relative to pure Ni } \\
\text { (lower melting range, less susceptible to gas porosity, etc.) }\end{array}$ & $\begin{array}{c}\text { Hast N variant (for } \\
\text { Te embrittlement } \\
\text { resistance) }\end{array}$ \\
\hline
\end{tabular}


Table 3 Selected properties of candidate clad material and base structural metal for MSRs
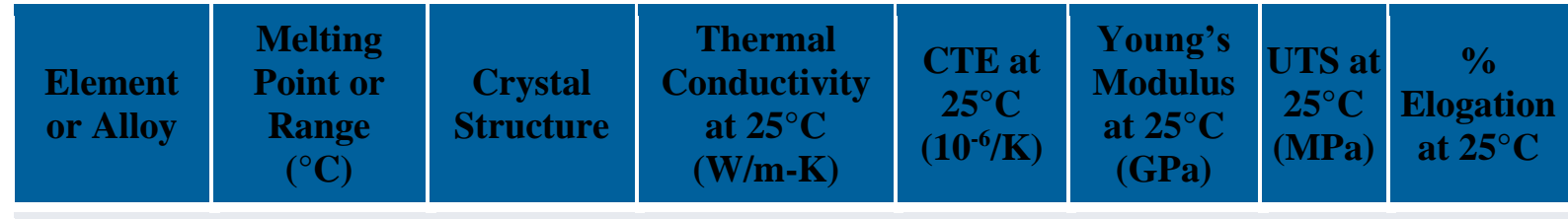

\begin{tabular}{|c|c|c|c|c|c|c|c|}
\hline \multicolumn{7}{|c|}{ Candidate clad materials } \\
\hline CP-W & 3422 & BCC & 160 & 4.5 & 411 & $\sim 1200$ & low \\
\hline Mo-TZM & 2623 & BCC & 142 & 4.8 & 325 & 750 & $15 \%$ \\
\hline Ni-201 & $1435-1446$ & FCC & 79.3 & 13.2 & 207 & 345 & $>40 \%$ \\
\hline Hast N & $1300-1400$ & FCC & 13.1 & 13.0 & 219 & 800 & $40 \%$ \\
\hline & & Candidate base structural materials & & \\
\hline $316 H$ & $1375-1400$ & FCC & 15.0 & 16.0 & 200 & 515 & $40 \%$ \\
\hline $800 H$ & $1357-1385$ & FCC & 10.6 & 14.2 & 196 & 531 & $50 \%$ \\
\hline 617 & $1332-1380$ & FCC & 13.4 & 11.6 & 211 & 734 & $60 \%$ \\
\hline
\end{tabular}
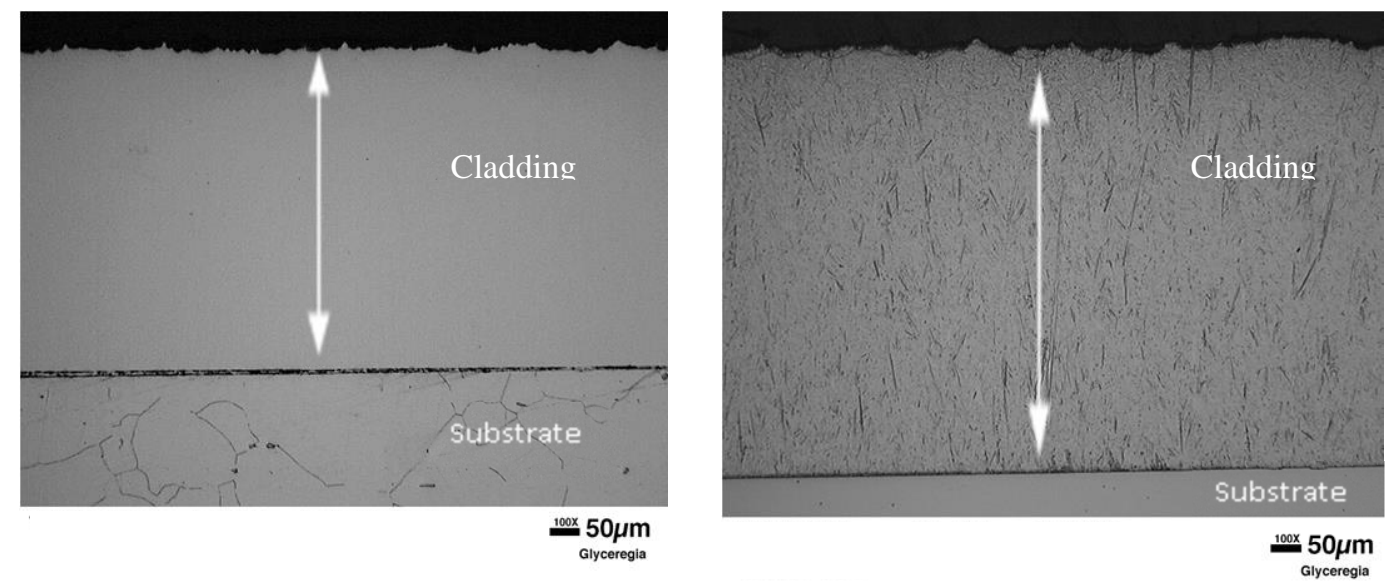

Figure 6 Lack of interface bonding/adhesion by chemical vapor deposition process (a) Ni cladding on an Alloy $800 H$ substrate, (b) Ni cladding on an Alloy 617 substrate [23].

\section{SUMMARY}

Cladding or overlaying of corrosion resistant materials on existing code qualified base metals could be an attractive option for MSR coolant boundary components and core support structures. It could potentially shorten the development and deployment time lines for molten salt reactors. In consideration of the candidate structural materials and candidate cladding materials, a survey of the fabrication practices of cladded components from nuclear and non-nuclear industry was conducted, to establish the reference point for the development and deployment of cladding MSR components and structures. Ni based cladding materials are expected to be readily applied for MSR with today's cladding technologies. On the other hand, cladding W and Mo based cladding materials on MSR structural materials are much more 
challenging, based on today's cladding technologies and industry experience and capability. Developing new cladding technologies for W and Mo based materials are essential for their successful use in MSR.

This report fulfills the FY18 milestone M4NT-18OR070502031: "Complete a survey on fabrication practice of cladded components from nuclear and non-nuclear industry" under the ORNL work package NT-18OR07050203 - Cladded Component Design and Fabrication Practice - ORNL.

\section{REFERENCES}

1 ASTM A265-12 "Standard Specification for Nickel and Nickel-Base Alloy-Clad Steel Plate," ASTM International, 2004.

2 ASTM B898-11 "Standard Specification for Reactive and Refractory Metal Clad Plate" ASTM International, 2004.

3 F. Gillemot, (2010) “Overview of reactor pressure vessel cladding," Int J Nuclear Knowledge Management 4(4):265 - 278.

4 ASM Handbook, ASM International, 2005.

5 J.R. Davis, ASM Specialty Handbook, Stainless Steels. ASM International, 1994.

6 BP Group, "Guidance on Industry Standard for Integral Cladding, Weld Overlay, and Limited Loose Lining of Pressure Vessels and Components," Document No GIS 36-107.

7 JFE, "CLAD Steel Plate", JFE Steel Cooperation.

8 L. Smith, (2012) "Engineering with CLAD Steel”. Nickel Institute Technical Series No 10064.

9 Z. Feng, T. Liu and Y Wang (2018) "Initial Assessment of Physical and Mechanical Properties of Clad/Base Metal Systems," Oak Ridge National Laboratory, Technical Report ORNL/TM-2018/966.

10 G. Banker and E.G. Reinke, Explosion We1ding, Welding, Brazing, and Soldering, Vol 6, ASM Handbook, ASM International, 1993, p 303-305

11 V.D. Linse, Procedure Development and Process Considerations for Explosion Welding, Welding, Brazing, and Soldering, Vol 6, ASM Handbook, ASM International, 1993, p 896- 900

12 R.A. Patterson, Fundamentals of Explosion Welding, Welding, Brazing, and Soldering, Vol 6, ASM Handbook, ASM International, 1993, p 160-164.

13 R. Srinivasan and C. S. Hartley, "Coextrusion," in ASM Handbook (ASM International, 2005), 14A: 505-515.

14 R. C. Tucker, Jr, "Thermal Spray Coatings," in ASM Handbook (ASM International, 1994), 5: 497- 509.

15 G. A. Di Bari, "Nickel Plating," in ASM Handbook (ASM International, 1994), 5: 201-212.

16 T. Mooney, "Electroplated Coatings," in ASM Handbook (ASM International, 2003), 13A: 772-785.

17 D. W. Baudrand, "Electroless Nickel Plating," in ASM Handbook (ASM International, 1994), 5: 290-310.

18 D. M. Mattox, "Vacuum Deposition, Reactive Evaporation, and Gas Evaporation," in ASM Handbook (ASM International, 1994), 5: 556-572.

19 S. L. Rohde, "Sputter Deposition," in ASM Handbook (ASM International, 1994), 5: 573-581.

20 H. O. Pierson, "Chemical Vapor Deposition of Nonsemiconductor Materials," in ASM Handbook (ASM International, 1994) 5: 510-516.

21 S. Sham and G. Young, "Corrosion Resistant Claddings for Molten Salt Reactors", Unpublished Document, MSR Advanced Reactor Materials Program. Many 2018.

22 Guo, S, Zhang, J, Wu, W, Zhou, W. (2018) Corrosion in the molten fluoride and chloride salts and materials development for nuclear applications. Progress in Materials Science, 97:448-487.

23 G. Muralidharan, D.F. Wilson, L.R Walker, M.L. Santella, and D.E. Holcomb (2011) "Cladding Alloys for Fluoride Salt Compatibility," ORNL technical report ORNL/TM-2011/95. 